\title{
Somatic cell nuclear transfer
}

\author{
I. Wilmut*, N. Beaujean*, P. A. de Sousa*, A. Dinnyes*†, T. J. King*, L. A. Paterson*, D. N. Wellsł \& L. E. Young*† \\ * Roslin Institute, Roslin, Midlothian EH25 9PS, UK \\ \pm AgResearch Ltd, PB3123, Hamilton, New Zealand \\ $\dagger$ Present addresses: Research Group for Animal Breeding,Hungarian Academy of Sciences\& Szent István University, Hungary (A.D.); and \\ School of Human Development, Division of Reproductive Medicine, Queens Medical Centre, Nottingham NG7 2UH, UK (L.E.Y.).
}

\section{Abstract}

Cloning by nuclear transfer from adult somatic cells is a remarkable demonstration of developmental plasticity. When a nucleus is placed in oocyte cytoplasm, the changes in chromatin structure that govern differentiation can be reversed, and the nucleus can be made to control development to term.

\section{Introduction}

Cloning by present methods is very inefficient owing to the extraordinary demands placed on the oocyte cytoplasm in reprogramming a somatic nucleus rather than a sperm nucleus. The cumulative loss observed throughout development is assumed to reflect inappropriate expression of many genes whose harmful effect is exerted at different stages of development. These fundamental limitations to cloning are being addressed by analyses of the underlying cellular mechanisms. In time, this information may be used in the development of treatments to cause cells of one phenotype to 'transdifferentiate' to another.

Several laboratories have used a variety of somatic cell types to create cloned sheep, cattle, mice, pigs, goats, rabbits and cats (results are summarized in ref. 1). However, those laboratories have failed so far to obtain offspring in other species, including the rat, rhesus monkey and dog. Consistent among all published research is that only a small proportion of embryos reconstructed using adult or fetal somatic cells developed to become live young, typically between 0 and $4 \%$. The low overall success rate is the cumulative result of inefficiencies at each stage of the process (Fig. 1).

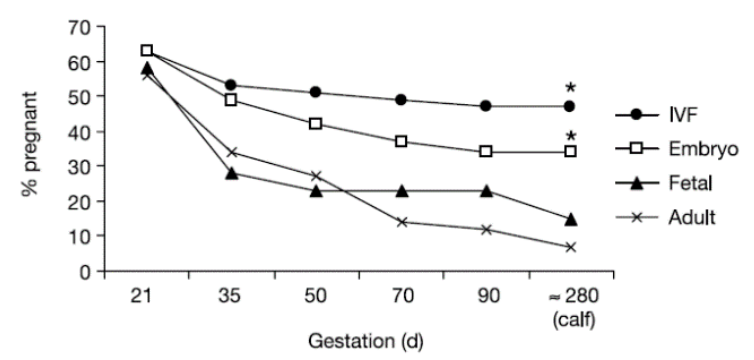

\section{Figure 1}

A comparison of survival to term of bovine embryos produced either by in vitro fertilization or nuclear transfer from embryos, fetal or adult fibroblasts. (Data from ref. 5.) *Including one twin calving from a single embryo transfer.

\section{Fetal loss and pathologies of cloned offspring}

In addition to embryonic loss, somatic cell nuclear transfer is also associated with very high rates of fetal, perinatal and neonatal loss, and production of abnormal offspring. Not all of these effects are due solely to nuclear transfer as similar problems are reported after embryo culture2.

Typically, at least one-third of the cattle and sheep confirmed pregnant with cloned embryos lose their fetuses during gestation $_{1}$. Abnormal development of the placenta, including vascular reduction, is a principal contributor to loss particularly during early pregnancy in sheep and cattle3. It may also contribute to some of the defects reported in neonates4. In cattle the rate of loss is also increased in the second and third trimesters of pregnancy after nuclear transfer (compared with in vitro fertilization (IVF)), with greater losses when adult rather than fetal or embryonic nuclei are used5. The over accumulation of placental fluid in hydroallantois occurs rarely in natural cattle pregnancies, but can affect up to $2 \%$ and $40 \%$ of pregnancies established with $\mathrm{IVF}_{6}$ and cloned embryos7, respectively. In cloned mice, the placentae are often 2-3-fold heavier than from natural mating, although a lack of vascularization has not been reported.

Many cloned offspring die within the first $24 \mathrm{~h}$ of birth (Table 1). Common anomalies include respiratory distress, increased birth weight and major cardiovascular abnormalities that can result in gross distension of the liver and dilated major vessels. Some of these anomalies may be secondary effects of another abnormality. The production of oversized offspring after nuclear transfer in ruminants mimics the findings following other embryo manipulations when increased 
birth weight is the most readily recognized characteristic of the 'large offspring syndrome'2. Other common characteristics include prolonged gestation, fluid accumulation, enlargement of organs, sluggish onset of labour and difficulty in breathing.

\begin{tabular}{|c|c|c|c|c|c|c|c|c|c|}
\hline Species & $\begin{array}{l}\text { Type of embryo } \\
\text { manipulation }\end{array}$ & Embryo loss & Gestation length & $\begin{array}{c}\text { Placental } \\
\text { abnormalities }\end{array}$ & Fetal size & $\begin{array}{c}\text { Respiratory/cardiovascular } \\
\text { dysfunction }\end{array}$ & Organ dysplasia & $\begin{array}{l}\text { Perinatal } \\
\text { mortality }\end{array}$ & $\begin{array}{l}\text { Post-natal } \\
\text { development }\end{array}$ \\
\hline \multirow[t]{2}{*}{ Cow } & Nuclear transfer & High & Prolonged & Common & Increases & Common & Common & Raised & Altered \\
\hline & Other & High & Prolonged & Common & Increases & Occasional & Occasional & Raised & Altered \\
\hline \multirow[t]{2}{*}{ Sheep } & Nuclear transfer & High & Prolonged & Common & Increases & Common & Common & Raised & Altered \\
\hline & Other & High & Prolonged & Common & Increases & - & Occasional & Raised & Altered \\
\hline \multirow[t]{2}{*}{ Goat } & Nuclear transfer & High & Prolonged & None observed & Normal & No & No & Normal & Normal \\
\hline & Other & High & Normal & None observed & Normal & No & No & Normal & Normal \\
\hline \multirow[t]{2}{*}{ Pig } & Nuclear transfer & High & Prolonged & None observed & Reductions & Occasional & Occasional & Raised & Altered \\
\hline & Other & High & Normal & None observed & Reductions & No & No & Raised & Normal \\
\hline \multirow[t]{2}{*}{ Mouse } & Nuclear transfer & High & Caesareans & Common & Altered & Common & - & Raised & Altered \\
\hline & Other & High & - & - & Reduced & - & - & - & Altered \\
\hline
\end{tabular}

There has not been an adequate assessment of post-natal development of clones. Abnormalities that have been described include failure of the immune system, structural abnormalities of the brain, digestive dysfunction, enteritis and umbilical infections. There is a suggestion that the fate of cloned individuals may be influenced by genetic background or donor cell type. In two independent studies in which the strains of mice used differed, mice cloned from cumulus cells became obese in adult life ${ }_{9}$ whereas those from Sertoli cells of immature mice died at an unusually early age 10 . The fact that the obesity was not heritable after sexual reproduction provides direct evidence that failures associated with cloning are epigenetic9. By contrast, physiological studies of cloned calves suggest normality, at least for the tests examined ${ }_{11}$. However, the eldest of these animals was only 4 years at the time of the tests and it is important that studies extend throughout a lifespan, which is potentially more than 15 years.

\section{Cellular factors influencing outcome}

\section{Maintenance of ploidy}

Normal development of cloned embryos depends on maintaining normal ploidy by coordinating the cell cycles of the recipient oocyte and donor nucleus (see ref. 12 for review). Three effective strategies have been defined. When using mammalian oocytes arrested at metaphase II as the recipient cells, normal ploidy is maintained if the donor nucleus is awaiting DNA replication (G0 or G1). Alternatively, advantage may be taken of the fact that ploidy is also changed if chromosomes are shed in a polar body. Following transfer of G2/M-phase nuclei (4C) into enucleated metaphase II mouse oocytes13, expulsion of a polar body returns the reconstructed embryo to normal ploidy of $2 \mathrm{C}$, provided that cytochalasin B is omitted from the culture medium. In the third strategy, an interphasic donor nucleus may be at any stage of the cycle if the metaphase II oocyte is activated before transfer and M-phase promoting factor (MPF) levels decline. However, cytoplasts with basal levels of MPF may not be optimal for reprogramming somatic nuclei 14 . Although these general principles were established quickly, it seems probable that there is much to learn of the detailed mechanisms in different species. Rabbits were successfully cloned only when adjustments were made to accommodate for the rapid progression through the first cell cycle in that species 15.

\section{Donor cell cycle stage}

Although few precise comparisons have been made, there appears to be a 'window of opportunity' in the cycle of donor cells, spanning G2/M/G1/G0 phases, when nuclear reprogramming is more effective. Dolly (the first successful clone of an adult animal) was created from a donor cell induced to quiescence by serum deprivation 16 , and since then many other offspring have been produced using cells that were expected to be quiescent. Three studies have now carefully selected cells in G1 and contrasted them with cells in G0 (refs 7, 17, 18). All three studies obtained calves from cells in G1, although in one case no calves were derived with fetal cells using the well-proven techniques in G0 (ref. 17). The other two studies, however, showed a 3-7-fold increase in the production of viable offspring with embryos derived from adult quiescent cells $(\mathrm{G} 0)_{7,18}$. Donor cells at metaphase may be considered optimally compatible with metaphase II oocytes and have resulted in improved rates of blastocyst development using murine embryonic stem (ES) cells, as opposed to interphasic nuclei; however, the post-implantation development was then characterized by a high mortality 19. Determining optimal cell cycle stage of the donor cell is of great practical importance and would also focus mechanistic research.

\section{Delayed activation}

After nuclear transfer, an activation stimulus triggers development. It was initially considered that the direct exposure of chromosomes to factors in the oocyte cytoplasm before activation 20 and allowing time for the re-assembly of the nuclear apparatus required for the cell cycle 21 might aid development. Although delaying oocyte activation after nuclear transfer can enhance development in cattle and mice, it is not essential in these species 14,22 . 
In general there is a decrease in the proportion of embryos becoming offspring when donor nuclei are obtained from later stages of development. The change is assumed to reflect the degree of cellular differentiation and epigenetic constraints. The proportion of mouse embryos that developed to offspring with transferred blastomere nuclei from 2-, 4and 8-cell stage embryos decreased from $22 \%, 14 \%$ and $8 \%$, respectively 23. Embryonic survival decreases further with pluripotent mouse ES cells (2-11\%) and somatic cells in G0/G1 (1-3\% (ref. 1)). The reduction in efficiency occurs later in cattle, as the proportion of transferred bovine cloned embryos that developed into live offspring from morulae, fetal and adult fibroblasts was $28 \%, 13 \%$ and 5\%, respectively (Fig. 1). Differences between species are associated with the later onset of major transcription from the embryonic genome in ruminants than mice 24 . This may mean that developmental changes in chromatin structure take place later in ruminant development and so less remodelling is required in cleavage stage embryos. Additionally, after nuclear transfer more time and cell cycles are available for remodelling before transcription begins in ruminants. Recent observations in mice using fetal neural cells as nuclear donors have also suggested a loss of developmental totipotency with neural differentiation 25 . However, terminal differentiation- associated DNA rearrangements25 may not be incompatible with nuclear totipotency as evidenced by successful cloning from terminally differentiated lymphocytes 26 . In mice, differences in the pattern of fetal loss when using hybrid and inbred donor cells were particularly apparent with ES cells as nuclear donors, and efficiency was also lower when inbred cumulus cells were used 27 .

\section{Molecular mechanisms}

The unique pattern of mortality during embryonic, fetal and neonatal stages in clones apparently reflects the inappropriate expression of genes whose effect is exerted at different stages of development and can be fatal. Perturbations in the expression of imprinted genes associated with phenotypic defects have now been observed in sheep, cattle and mice. Many imprinted genes have critical roles in regulating growth during fetal development; furthermore, the common characteristics of the large offspring syndrome were recognized as being similar to those clinical and experimental situations in which the expression or effect of $\mathrm{H} 19$ and/or insulin-like growth factor II (IGF2) is perturbed2. Expression of IGF2 receptor (IGF2R) was reduced in the liver, kidney, heart and muscle of unusually large sheep fetuses resulting from embryo culture 28 . The change in expression was associated with a loss of methylation at a differentially methylated region involved in regulation of gene imprinting. Unexpectedly, there was no change in expression of IGF2 or $\mathrm{H} 19$.

Mouse fetuses derived by nuclear transfer from ES cells display aberrant expression of H19, Igf2 and other imprinted genes known to have important roles in fetal or placental development. Some mice cloned from ES cells survive until adulthood and appear phenotypically normal despite epigenetic aberrations in at least one of the six imprinted genes that were examined29. Evidently 'normal' life is possible despite considerable variation in gene expression, and this probably depends on the particular gene affected, its degree and nature of perturbation, effects of redundancy, and on speciesspecific variation in susceptibility to any single imprinted gene disruption. However, rather than being the consequence of nuclear transfer, the imprinting status of the cloned mice examined in ref. 29 may be due to the epigenetic instability inherent to ES cell lines. When somatic cells were used as nuclear donors in mice, imprinting errors were not detected in the phenotypically normal fetus; however, the level of expression of several genes was elevated and imprinting errors were observed in their overgrown placentae 30 .

Apart from the improper expression of imprinted genes, the dysregulation of non-imprinted genes also occurs in clones 31 . However, two measures of the correct reprogramming of gene expression have been reported elsewhere. In female somatic cells, reactivation of the inactive X chromosome can occur in early embryos after nuclear transfer, and reprogramming of telomerase activity can allow restoration of telomere length in cloned animals (reviewed in ref. 32).

\section{Epigenetic regulation of gene expression}

Errors leading to inappropriate expression could arise at any of the levels at which regulation of gene expression occurs, including the organization of the nucleus, chromatin structure and the availability of regulatory molecules. Chromatin proteins regulate access of the transcription machinery to chromosomal DNA and so ultimately determine the pattern of gene expression. This chromosomal infrastructure is far more dynamic than had been understood previously, adding to the impression that nuclear and chromosome structure are in a continual state of flux 33 . A large number of structural proteins and enzymes that modify chromatin structure have been identified and are principal candidates for regulating early reprogramming events.

The linker histone $\mathrm{H} 1$ may be involved in the regulation of gene expression in early embryos (reviewed in ref. 34). The somatic form of histone $\mathrm{H} 1$ is apparently absent or in very low concentration in oocytes and early embryos, but becomes detectable when major transcriptional activation of the embryonic genome occurs. Somatic H1 is lost from most mouse nuclei soon after transfer, but the cell cycle stage of donor and recipient cells influences the rate of loss 35 . Enzymatic modifications of histones include phosphorylation, methylation, acetylation and ubiquitination, or the removal of these 
modifications36. These modifications are recognized by other structural proteins and enzymes, which together may stabilize the pattern of gene expression.

Chromatin remodelling is also achieved by multisubunit ATP-dependent enzymes (reviewed in ref. 36). The helicase activity of these enzymes is able to expose DNA or redistribute nucleosomes in a tissue-specific manner. The loss of a principal component of the basal transcriptional complex from somatic nuclei incubated in frog oocyte extract provided the first indication that members of the SWI/SNF family of enzymes may have roles in the development of cloned embryos 37 .

Finally, methylation of $\mathrm{CpG}$ dinucleotides in chromosomal DNA provides a genome-wide means of regulation, usually associated with the inheritance of lineage-specific gene silencing between cell generations (reviewed in ref. 38). Widespread disruptions in DNA methylation have now been described in cloned embryos of mice and cattle (reviewed in ref. 39), suggesting that present methods of cloning are disruptive and that the effects are complex. In cloned cattle embryos, the highly methylated status of the donor cells was retained through several cell divisions. There was great variation between cloned embryos consistent with the variation in stage and cause of death of cloned embryos. In contrast, in the pig, changes in methylation of short interspersed element sequences were similar to those observed after in vitro fertilization, although at the 4-8-cell stage both were more extensively methylated than in embryos fertilized in vivo (reviewed in ref. 39).

Together these observations emphasize the need for further studies of different regions of the genome with different donor cells and methods of nuclear transfer in several species. It is critical not to assume that mammalian preimplantation events (and therefore reprogramming of a somatic nucleus) are the same in all species. The rapid demethylation of the paternal genome that is seen in several species does not occur in the sheep (Fig. 2: N.B., I.W., R. R. Meehan and L.E.Y., unpublished data).
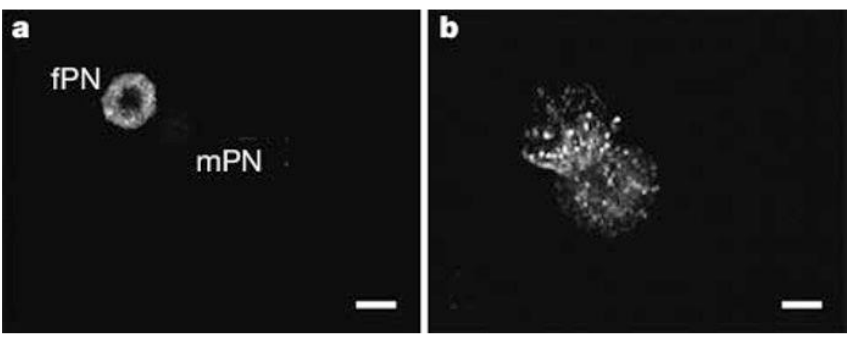

Figure 2

5-Methyl cytosine immunostaining of pronuclear DNA in mouse and sheep zygotes. a, Mouse 1-cell embryo $14 \mathrm{~h}$ after fertilization. Only the female pronucleus (fPN) is stained. $\mathrm{mPN}$ indicates position of the male pronucleus. b, Sheep 1-cell embryo $22 \mathrm{~h}$ after fertilization. In marked contrast to the mouse, the paternal pronucleus does not undergo demethylation and both pronuclei are stained. Scale bar, $10 \mathrm{~mm}$

\section{The future}

As the fate of cloned embryos is determined by molecular events within hours of nuclear transfer, it is disappointing that so little is known about these events during the early development of cloned embryos. During somatic cell nuclear transfer a great deal is asked of the molecular mechanisms that have evolved to regulate fertilization and pregnancy. Viewed in this light, it is still surprising that somatic cell cloning ever produces viable offspring. Although some improvements in efficiency are to be expected from optimization of present procedures, greater benefits might be expected from intervention to assist reprogramming of the transferred nucleus. At present the means to enhance the success of nuclear transfer are not known, but may involve the use of remodelling complexes and factors that remove somatic epigenetic modifications before transfer. In addition to application of this information in nuclear transfer, new understanding of mechanisms that regulate developmental plasticity will lead to methods to change cells of one phenotype to another as a means of providing histocompatible cells for treatment of degenerative diseases. A new era of developmental biology and regenerative medicine awaits.

Acknowledgements We each acknowledge discussions with colleagues during the development of these ideas and are grateful for funding from the governments, charities and commercial agencies acknowledged in our research papers.

\section{References}

1. Wilmut, I. \& Peterson, L. A. Somatic cell nuclear transfer (cloning) efficiency [online] khttp://www.roslin.ac.uk/public/webtablesGR.pdfl (2002)

2. Young, L. E. \& Fairburn, H. R. Improving the safety of embryo technologies: possible role of genomic imprinting. Theriogenology 53, 627-648 (2000).

3. Hill, J. R. et al. Evidence for placental abnormality as the major cause of mortality in first-trimester somatic cell cloned bovine fetuses. Biol. Reprod. 63, 1787-1794 (2000),

4. Hill, J. R. et al. Clinical and pathologic features of cloned transgenic calves and fetuses (13 case studies). Theriogenology 51, 1451-1465 (1999).

5. Heyman, Y. et al. Frequency and occurrence of late-gestation losses from cattle cloned embryos. Biol. Reprod. 66, 6-13 (2002).

6. Hasler, J. F. et al. Production, freezing and transfer of bovine IVF embryos and subsequent calving results. Theriogenology 43, 141-152 (1995).

7. Wells, D. et al. Proc. 32nd Ann. Conf. Soc. Reprod. Biol. Abstract No. 25 (2001).

8. Tanaka, S. et al. Placentomegaly in cloned mouse concepti caused by expansion of the spongiotrophoblast layer. Biol. Reprod. 65, 1813-1821 (2001).

9. Tamashiro, K. L. et al. Cloned mice have an obese phenotype not transmitted to their offspring. Nature Med. 8, 262-267 (2002).

10. Ogonuki, N. et al. Early death of mice cloned from somatic cells. Nature Genet. 30, 253-254 (2002).

11. Lanza, R. P. et al. Cloned cattle can be healthy and normal. Science 294, 1893-1894 (2001).

12. Campbell, K. H., Loi, P., Otaegui, P. J. \& Wilmut, I. Cell cycle co-ordination in embryo cloning by nuclear transfer. Rev. Reprod. 1, 40-46 (1996).

13. Ono, Y., Shimozawa, N., Ito, M. \& Kono, T. Cloned mice from fetal fibroblast cells arrested at metaphase by a serial nuclear transfer. Biol. Reprod. 64, 44-50 (2001). 
14. Wakayama, T. \& Yanagimachi, R. Effect of cytokinesis inhibitors, DMSO and the timing of oocyte activation on mouse cloning using cumulus cell nuclei. Reproduction 122 , 49-60 (2001).

15. Chesne, P. et al. Cloned rabbits produced by nuclear transfer from adult somatic cells. Nature Biotechnol. 20, 366-369 (2002)

16. Wilmut, I., Schnieke, A. E.,McWhir, J., Kind, A. J. \& Campbell, K. H. S. Viable offspring derived from fetal and adult mammalian cells. Nature 385, 810-813 (1997).

17. Kasinathan, P., Knott, J. G., Wang, Z., Jerry, D. J. \& Robl, J. M. Production of calves from G1 fibroblasts. Nature Biotechnol. 19, 1176-1178 (2001).

18. Wells, D. et al. Proc. Curr. Status Perspec. Cloning Stud. 73 (National Institute of Agrobiological Sciences, Tsukuba, Japan, 2001).

19. Zhou, Q., Jouneau, A., Brochard, V., Adenot, P. \& Renard, J. P. Developmental potential of mouse embryos reconstructed frommetaphase embryonic stem cell nuclei. Biol. Reprod. 65 , $412-419(2001)$.

20. Campbell, K. H. S., McWhir, J., Ritchie, W. A. \& Wilmut, I. Sheep cloned by nuclear transfer from a cultured cell line. Nature 380, 64-66 (1996).

21. Wakayama, T. Perry, A. C. F., Zuccotti, M., Johnson, K. R. \& Yanagimachi, R. Full-term development of mice from enucleated oocytes injected with cumulus cell nuclei. Nature 394, 369-374 (1998)

22. Kubota, C. et al. Six cloned calves produced from adult fibroblast cells after long-term culture. Proc.Natl Acad. Sci. USA 97, 990-995 (2000).

23. Cheong, H. T., Takahashi, Y. \& Kanagawa, H. Birth of mice after transplantation of early cell-cyclestage embryonic nuclei into enucleated oocytes. Biol. Reprod. 48, 958-963 (1993).

24. Thompson, E. M. Chromatin structure and gene expression in the preimplantation mammalian embryo. Reprod. Nutr. Dev. 36, 619-635 (1996).

25. Yamazaki, Y. et al. Assessment of the developmental totipotency of neural cells in the cerebral cortex of mouse embryo by nuclear transfer. Proc. Natl Acad. Sci. USA 98, 14022-

14026 (2001)

26. Hochedlinger, K. \& Jaenisch, R.Monoclonal mice generated by nuclear transfer frommature B and T cells. Nature 415, 967-969 (2002)

27. Wakayama, T. \& Yanagimachi, R. Mouse cloning with nucleus donor cells of different age and type. Mol. Reprod. Dev. 58, 376-383 (2001).

28. Young, L. E. et al. Epigenetic change in IGF2R is associated with fetal overgrowth after sheep embryo culture. Nature Genet. 27, 153-154 (2001).

29. Humpherys, D. et al. Epigenetic instability in ES cells and cloned mice. Science 293, $95-97$ (2001).

30. Inoue, K. et al. Faithful expression of imprinted genes in cloned mice. Science 295, 297 (2002).

31. Daniels, R., Hall, V. \& Trounson, A. O. Analysis of gene transcription in bovine nuclear transfer embryos reconstructed with granulose cell nuclei. Biol. Reprod. 63, 1034-1040 (2000).

32. Rideout, W. M., Eggan, K. \& Jaenisch, R. Nuclear cloning and epigentic reprogramming of the genome. Science 293, 1093-1098 (2001).

33. Misteli, T. Protein dynamics: implications for nuclear architecture and gene expression. Science 291, 843-847 (2001).

34. Clarke, H. J., McLay, D. W. \& Mohamed, O. A. Linker histone transitions during mammalian oogenesis and embryogenesis. Dev. Genet. $22,17-30$ (1998).

35. Bordignon, V., Clarke, H. J. \& Smith, L. C. Factors controlling the loss of immunoreactive somatic histone H1 from blastomere nuclei in oocyte cytoplasm: a potential marker of nuclear reprogramming. Dev. Biol. 233, 192-203 (2001).

36. Nakao, M. Epigenetics: interaction of DNA methylation and chromatin. Gene 278, 25-31 (2001).

37. Kikyo, N.,Wade, P. A., Guschin, D., Ge, H. \&Wolffe, A. P. Active remodeling of somatic nuclei in egg cytoplasm by the nucleosomal ATPase ISWI. Science 289, 2360-2362 (2000).

38. Robertson, K. D. \&Wolffe, A. P. DNA methylation in health and disease. Nature Rev. Genet. 1, 11-19 (2000).

39. Fairburn, H. R., Young, L. E. \& Hendrich, B. D. Epigenetic reprogramming: how now, cloned cow. Curr. Biol. 12, R68-R70 (2002). 